\title{
PLANEJAMENTO MUNICIPAL E ORGANIZAÇÃO DO TERRITÓRIO: A DINÂMICA RURAL - URBANA NO MUNICÍPIO DE CORUMBATAÍ-SP
}

\author{
Paulo Roberto Joia ${ }^{1}$
}

Resumo: Corumbataí é um pequeno município do interior Paulista, encravado em importantes eixos rodoviários. Ao longo de sua história, o município não conseguiu acompanhar a prosperidade que o estado de São Paulo obteve e permaneceu econômica e demograficamente estagnado. Este trabalho tem por objetivo analisar as transformações do espaço geográfico em diferentes períodos histórico da ocupação do território do município de Corumbataí e relacionar o processo de ocupação com a formação da rede urbana e a estrutura da integração intramunicipal, dando ênfase sobre a distribuição da população e das atividades econômicas. Constitui-se o objeto de análise deste trabalho o espaço natural e os aspectos socioeconômicos do município, fazendo um diagnóstico das características mais relevantes. É feita uma análise regional em diferentes aspectos do município e estabelecidas relações com as demandas da população e com o desenvolvimento local. Os dados levantados permitem estabelecer diretrizes para as políticas públicas municipais e para a elaboração do Plano Diretor Municipal. Conclui-se que o processo de interiorização da indústria, associado à expansão dos eixos rodoviários, torna-se um importante fator para a organização do espaço e para o desenvolvimento local.

Palavras-Chave: Organização do Espaço; Atividades Econômicas; Integração Regional; Desenvolvimento Local.

\section{MUNICIPAL PLANNING AND TERRITORIAL ORGANIZATION: THE RURAL URBAN DYNAMICS IN THE MUNICIPALITY OF CORUMBATAÍ-SP}

Abstract: Corumbataí is a small municipality in the Paulista hinterland, fitted in important road axes. Throughout its history, the municipality has failed to keep up with the prosperity that the state of São Paulo has achieved and has remained economically and demographically stagnant. The objective of this work is to analyze the transformations of the geographical space in different historical periods of the occupation of the territory of the municipality of Corumbataí and relate the occupation process to the urban network and the intramunicipality integration structure, with emphasis on the distribution of population and economic activities. It constitutes the object of analysis of this work the natural space and socioeconomic aspects of the municipality, making a diagnosis of the most relevant characteristics. A regional analysis is made in different aspects of the municipality and relationships are established with the demands of the population and local development. The data collected allows the establishment of guidelines for municipal public policies and for

\footnotetext{
${ }^{1}$ Professor Titular do Curso de Geografia da Universidade Federal do Mato Grosso do Sul (UFMS) - Campus de Aquidauana. Email: paulo.joia@ufms.br
} 
the elaboration of the Municipal Master Plan. It is concluded that the process of interiorization of the industry, associated with the expansion of the highway axes, becomes an important factor for organization of space and local development.

Keywords: Space Organization, Economic Activities, Regional Integration, Local Development.

\section{INTRODUÇÃO}

O município de Corumbataí ocupa uma área de $278,6 \mathrm{~km}^{2}$ e abrigava, em 2018 , uma população estimada de 4.047 habitantes, com números pouco expressivos para o total de habitantes do estado de São Paulo.

As atividades econômicas predominantes estão voltadas para a agropecuária (pecuária bovina e cana-de-açúcar), com destaque também para a silvicultura (eucalipto) e a mineração de areia. A representatividade da indústria é muito pequena, apesar do município estar inserido em uma das regiões mais industrializadas do estado de São Paulo e de melhor logística de transporte, situada num quadrilátero formado pelas rodovias: Anhanguera (SP 330), Washington Luís (SP 310), Deputado Rogê Ferreira (SP 225) e Fausto Santomauro (SP 127), em um dos principais entroncamentos rodoviários do estado.

O município de Corumbataí é conhecido regionalmente e nacionalmente por emprestar o nome a dois importantes aspectos físicos, geograficamente estudados: 0 rio Corumbataí, que atravessa o território de oito municípios Paulistas, e a Formação Geológica Corumbataí, que está presente no substrato rochoso de diversos municípios Paulistas.

O processo de ocupação humana do território municipal, iniciado no final do século XIX, está associado à expansão da lavoura de café, à expansão das ferrovias e à política de imigração estrangeira para o interior Paulista.

Este trabalho tem por objetivo analisar as transformações do espaço geográfico no município de Corumbataí em diferentes períodos do processo de ocupação de seu território. Para a análise dos aspectos socioeconômicos, foi elaborado um formulário e utilizada a estratégia de distribuição para a comunidade escolar das escolas da rede pública do município (uma estadual e uma municipal) para ser preenchido pelo chefe da família. O resultado dessa enquete gerou uma pesquisa com 91 famílias, situadas em diversas áreas do município, sendo 41 na área urbana e 50 na área rural.

Constitui-se o objeto de análise deste trabalho a formação socioeconômica, o espaço natural, a rede urbana e o processo de integração regional do município de Corumbataí, localizado na Microrregião Geográfica de Rio Claro, no Estado de São Paulo. Utilizou-se a área territorial do município de Corumbataí como categoria de análise regional. Enfoques da Geografia Econômica e do Planejamento Regional foram dados à essa análise regional.

Admite-se como hipótese que o processo de desenvolvimento do território municipal de Corumbataí não acompanhou a prosperidade econômica do Estado de São Paulo nos diversos períodos da história econômica. No contexto regional, considerando a rede urbana, a sede municipal é classificada como uma cidade local, exercendo influência direta somente sobre seu próprio território. Neste sentido, considera-se que a fragilidade das forças locais não gerou o desenvolvimento econômico a ponto de superar os desequilíbrios regionais e as desigualdades sociais, restringindo as forças de transformação socioeconômicas ao território municipal. 


\section{FORMAÇÃO TERRITORIAL}

O município de Corumbataí localiza-se na porção central do Estado de São Paulo, fazendo parte da Microrregião Geográfica de Rio Claro. Em relação à região de planejamento e gestão, o município pertence à Região Administrativa de Campinas e à Região de Governo de Rio Claro. A sede do município situa-se às margens do rio Corumbataí, posicionado em uma altitude de $572 \mathrm{~m}$. Corumbataí dista $203 \mathrm{~km}$, por rodovia pavimentada, da cidade de São Paulo, capital do Estado.

O município possui uma extensão territorial de $278,6 \mathrm{~km}^{2}$. Os limites municipais são: ao norte, o município de Analândia; ao oeste, os municípios de Itirapina e Rio Claro; ao leste, os municípios de Santa Cruz da Conceição e Leme; e ao sul, o município de Rio Claro (Figura 1).

Figura 1. Corumbataí: localização e limites municipais

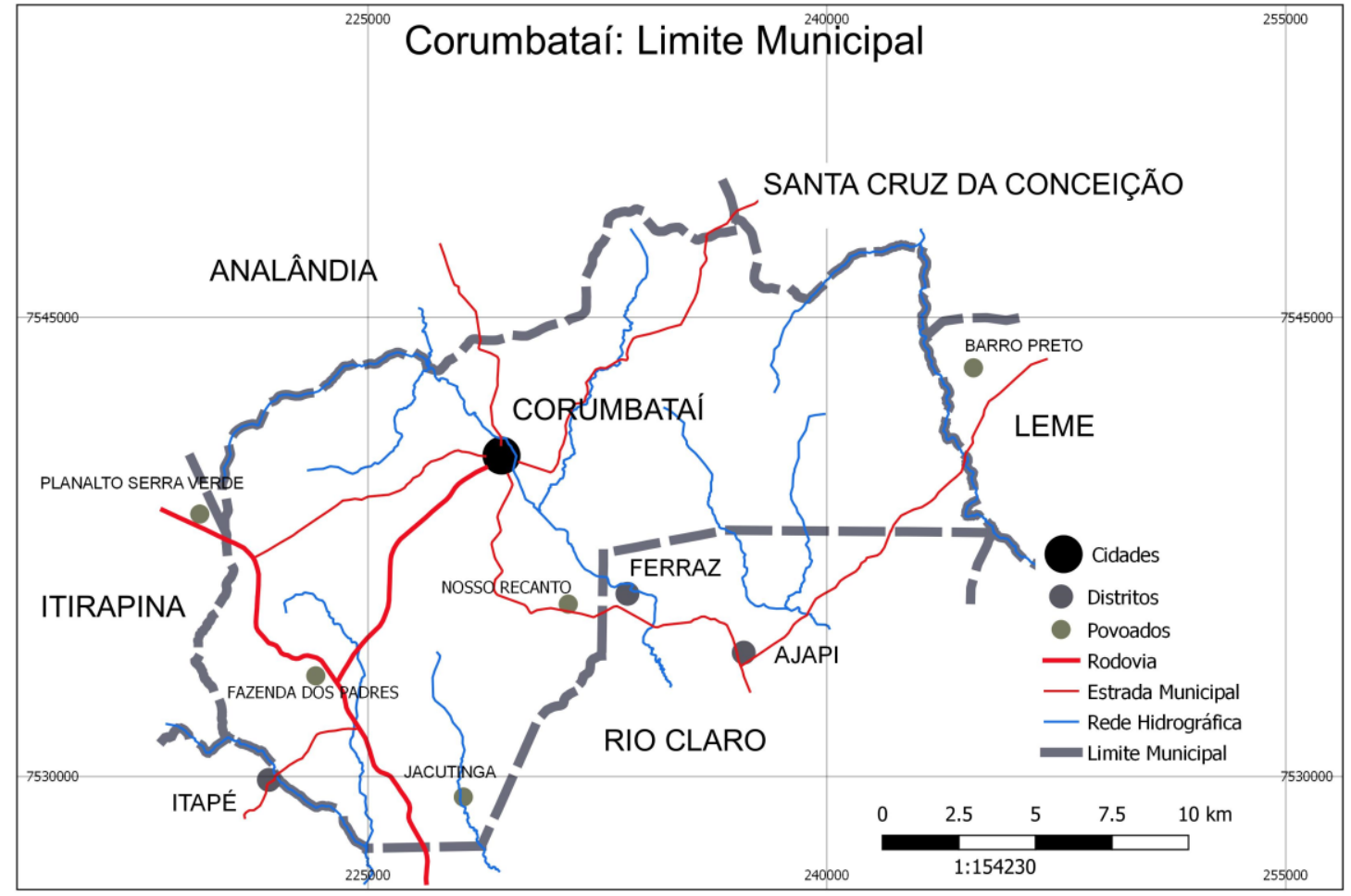

Fonte: o próprio autor, 2021

O município não possui nenhum distrito, entretanto em seu território encontramse os seguintes povoados: a) o bairro rural de Jacutinga, próximo à divisa com o município de Rio Claro; b) o aglomerado populacional denominado de Fazenda dos Padres, às margens da rodovia Washington Luís, que, segundo Petrone (1952, p. 26), poderia tornar-se "um núcleo inicial de um pequeno povoado, graças ao desenvolvimento da rodovia São Paulo - São José do Rio Preto (SP 310)"; e c) o núcleo populacional denominado Nosso Recanto, implantado no início dos anos 2000, às margens da rodovia municipal Nicolau Marotti, próximo à divisa com o município de Rio Claro. 
A origem do povoamento do território municipal ocorreu a partir da construção da estação ferroviária, em 1884, na ligação férrea entre as cidades de Rio Claro e São Carlos. O povoado desenvolveu-se somente a partir de 1905, quando o governo do Estado de São Paulo criou o Núcleo Colonial "Dr. Jorge Tibiriçá", para receber os imigrantes Europeus para trabalhar como colonos ou como trabalhadores rurais em diversos tipos de lavouras (FERLINI; FILLIPINI, 1992). Esse núcleo de povoamento estava inserido dentro do atual município de Corumbataí.

Em 1916, é construída uma nova linha férrea entre Rio Claro e São Carlos, deixando o antigo traçado como um ramal ferroviário de pouca expressão econômica (IBGE, 2016). Em 1966, o ramal ferroviário, que servia apenas as cidades de Corumbataí e Analândia, foi desativado com a justificativa de ser deficitário (GIESBRECHT, 2014).

Em 1919, o povoado foi elevado à categoria de Distrito de Paz, pertencente ao município de Rio Claro (IBGE, 2016). Em 24 de dezembro de 1948, pela Lei oㅡ 233, o Distrito de Paz de Corumbataí foi elevado à categoria de Município, desmembrandose de Rio Claro, e foram estabelecidas suas divisas intermunicipais com Analândia, Pirassununga, Leme, Rio Claro e Itirapina (SÃO PAULO, 1948).

Corumbataí torna-se mais um exemplo de cidade surgida e evoluída com o ciclo ferroviário no Estado de São Paulo, mas que após a erradicação dos ramais deficitários ficou às margens do novo eixo de transporte, o eixo rodoviário, cuja sede dista $9 \mathrm{~km}$ da rodovia principal, o que provocou uma desvalorização das atividades econômicas e do seu território.

\section{FORMAÇÃO SOCIOECONÔMICA}

Para Ortigoza (1992, p 54), "o município de Corumbataí apresentou no decorrer de sua história expulsão populacional, motivada pela intensa introdução do capital no campo e pela tendência à monocultura".

Petrone (1952, p 29), ao retratar a situação do município de Corumbataí na década de 1950, descreveu

"uma situação de abandono de imóveis rurais e urbanos, durante a década de 1940, provocada pelo êxodo rural em função do declínio das lavouras e do avanço da erosão do solo, fazendo com que a população passasse de 6.696 habitantes, em 1940, para 3.725, em 1950" (PETRONE, 1952, p 29).

O autor concluiu que o município, mesmo não sendo um centro comercial importante, apresentava sinais de progresso, entretanto com as transformações em nível regional, o mesmo apresentou-se "como centro decadente e sem vida" (PETRONE, 1952, p 25).

Com base no processo de ocupação do território e da periodização elaborada por Petrone (1952, p 15), traçou-se uma evolução socioeconômica para o município de Corumbataí, dividida em cinco períodos distintos: a) Fase Pioneira (1821 - 1905), vinculada à monocultura do café; b) Fase de Povoamento (1905 - 1948), associada à colonização estrangeira; c) Fase Emancipatória (1948 - 1966), quando ocorre a decadência da agricultura e é mantida a atividade pecuária; d) Fase de Estagnação (1966 - 1980), após a extinção da linha férrea; e) Fase de Revitalização (1980 - ), com a diversificação da economia (cana-de-açúcar, mineração, avicultura e turismo). 
No período atual, as atividades agrícolas predominantes no município são: cana-de-açúcar (açúcar e álcool), pastagens plantadas (bovinos), avicultura (corte e postura) e eucalipto (lenha e madeira), todas inseridas no agronegócio brasileiro.

Os principais recursos minerais explorados são: areia, para a construção civil e para fins industriais, argila, para a indústria cerâmica, e água potável de mesa (SANTOS, 2005).

No setor industrial, destacam-se algumas pequenas indústrias alimentares, metalúrgicas, de madeira (serrarias), de mineração (areeiros) e cerâmicas (olarias) (ZANARDI, 2007). Observou-se que a principal indústria metalúrgica do município, a Corumbataí Metais Ind. e Com. Ltda., que atuava na fundição de estanho, fundada em 1988, foi fechada em 1995, restando apenas as suas edificações.

A nova dinâmica econômica, observada a partir dos anos 1990, através da expansão da lavoura canavieira e da mineração de areia, "reposicionou o município de Corumbataí em uma estrutura de desenvolvimento regional" (OLIVEIRA, 2003, p 134) como fornecedor de produtos primários para o setor industrial.

No censo de 1950, logo após a emancipação do município, foram registrados em Corumbataí 3.725 moradores (LEITE; JOIA; FERREIRA, 1983). Em 2010, passados 60 anos, a população permaneceu em 3.874 habitantes, concluindo que houve um ínfimo acréscimo na população municipal durante seis décadas. Esta estagnação no número de habitantes é justificada pelo equilíbrio existente entre a corrente migratória de Nordestinos, dirigida para os trabalhos agrícolas, e a evasão populacional dos autóctones para outras cidades.

A população do município, em 2010, era de 3.874 hab., resultando numa densidade demográfica de $13,9 \mathrm{hab} / \mathrm{km}^{2}$, distribuída em 1.781 habitantes na zona rural e 2.093 na zona urbana. Para 2016, era estimada uma população de 4.045 hab. A população de idosos passou de 11\%, em 1980, para 13\%, em 2010 (IBGE, 2016).

Entre os municípios vizinhos, Corumbataí era o que apresentava a menor taxa de urbanização (Tabela 1). Vários fatores colaboraram para a permanência da população na zona rural, entre os quais pode ser citado a predominância de pequenas propriedades rurais, as distâncias relativamente pequenas entre as propriedades rurais e a cidade, o que permite deslocamentos diários, em curto intervalo de tempo, e a expansão de atividades não agrícolas no campo, como as de lazer. De acordo com o IBGE (2010), notou-se um equilíbrio entre o número de domicílio (particulares permanentes) na zona urbana (677) e na zona rural (537).

Tabela 1. Taxa de urbanização e ocupação dos domicílios em Corumbataí e municípios vizinhos (em 2010).

\begin{tabular}{|c|c|c|c|c|c|c|c|}
\hline$\frac{\frac{0}{0}}{\frac{0}{0}}$ & 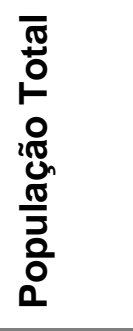 & 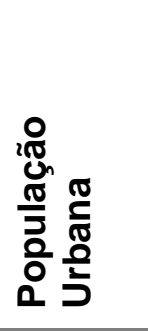 & 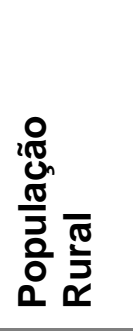 & 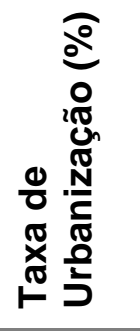 & 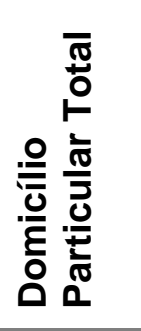 & 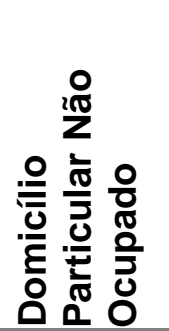 & 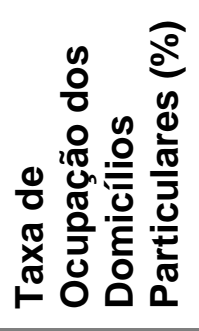 \\
\hline Corumbataí & 3.874 & 2.093 & 1.781 & 54,03 & 1.742 & 524 & 69,92 \\
\hline Analândia & 4.293 & 3.408 & 885 & 79,39 & 2.187 & 798 & 63,51 \\
\hline
\end{tabular}




\begin{tabular}{lrrrrrrr}
\hline $\begin{array}{l}\text { Santa Cruz } \\
\text { da } \\
\text { Conceição }\end{array}$ & 4.002 & 2.708 & 1.294 & 67,67 & 1.653 & 346 & 79,07 \\
\hline Leme & 91.756 & 89.862 & 1.894 & 97,94 & 30.839 & 2.851 & 90,76 \\
\hline Rio Claro & 186.253 & 182.720 & 4.533 & 97,57 & 67.316 & 7.504 & 88,85 \\
\hline Itirapina & 15.524 & 14.001 & 1.523 & 90,19 & 6.355 & 2.312 & 63,62 \\
\hline \multicolumn{7}{l}{ Fonte: IBGE (2010). }
\end{tabular}

Quanto à população residente no município de Corumbataí, $85 \%$ tinham por lugar de nascimento a região Sudeste e $15 \%$ as demais regiões do País, com destaque para a região Nordeste. Dos 3.874 moradores, em 2010, $21 \%$ passaram a residir no município nos últimos 5 anos, e desses novos moradores $74 \%$ dirigiram-se para a zona rural (IBGE, 2010). Esses dados foram confirmados com a pesquisa de campo, realizada em 2017, com a população local, onde se notou a grande diferença no local de residência entre os moradores que passaram a residir no município nos últimos 6 anos, sendo que os moradores que ser dirigiram para a zona urbana $(8,1 \%)$ e os que se dirigiram para a zona rural $(34,1 \%)$ (Figura 2).

Figura 2. Tempo de Residência: zona urbana e rural.

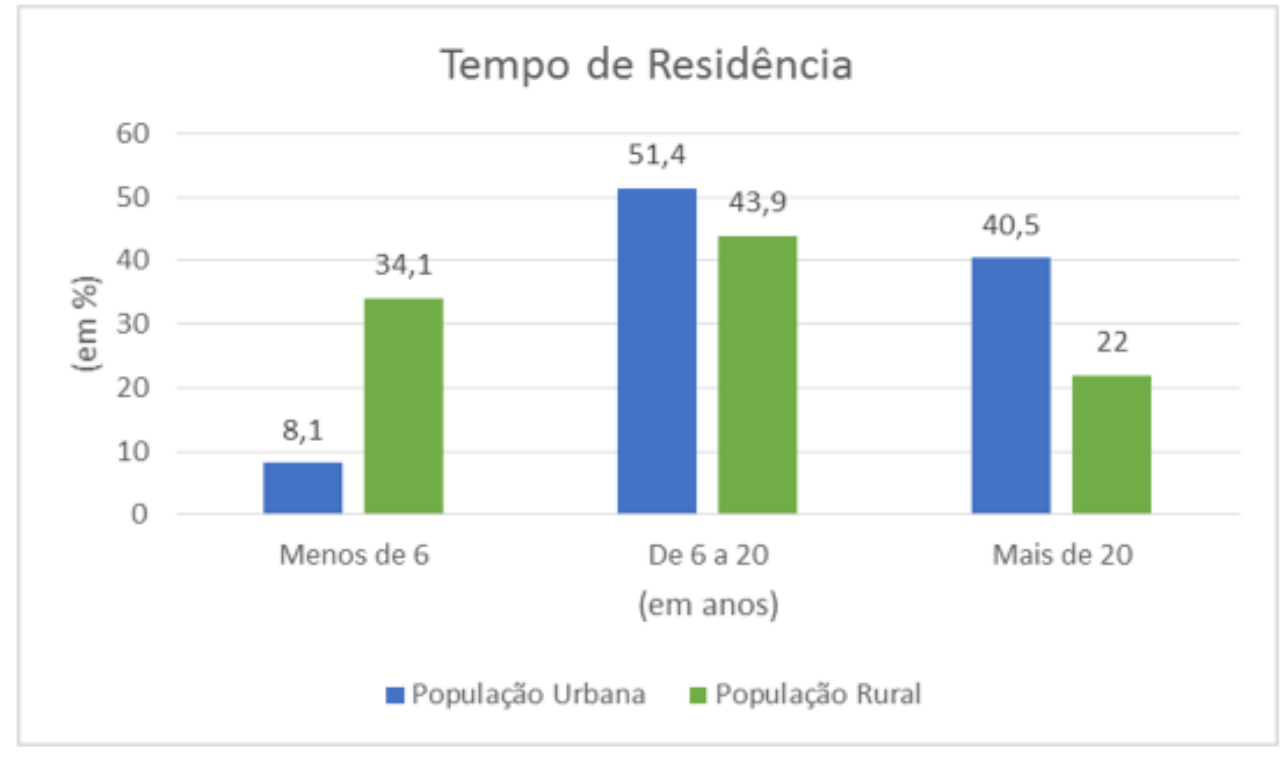

Fonte: o próprio autor, 2021

As diferenças socioeconômicas existentes entre a população urbana e rural também foram evidenciadas pela situação e condição de ocupação do domicílio (Figura 3).

Figura 3. Condições do Domicílio: zona urbana e rural. 


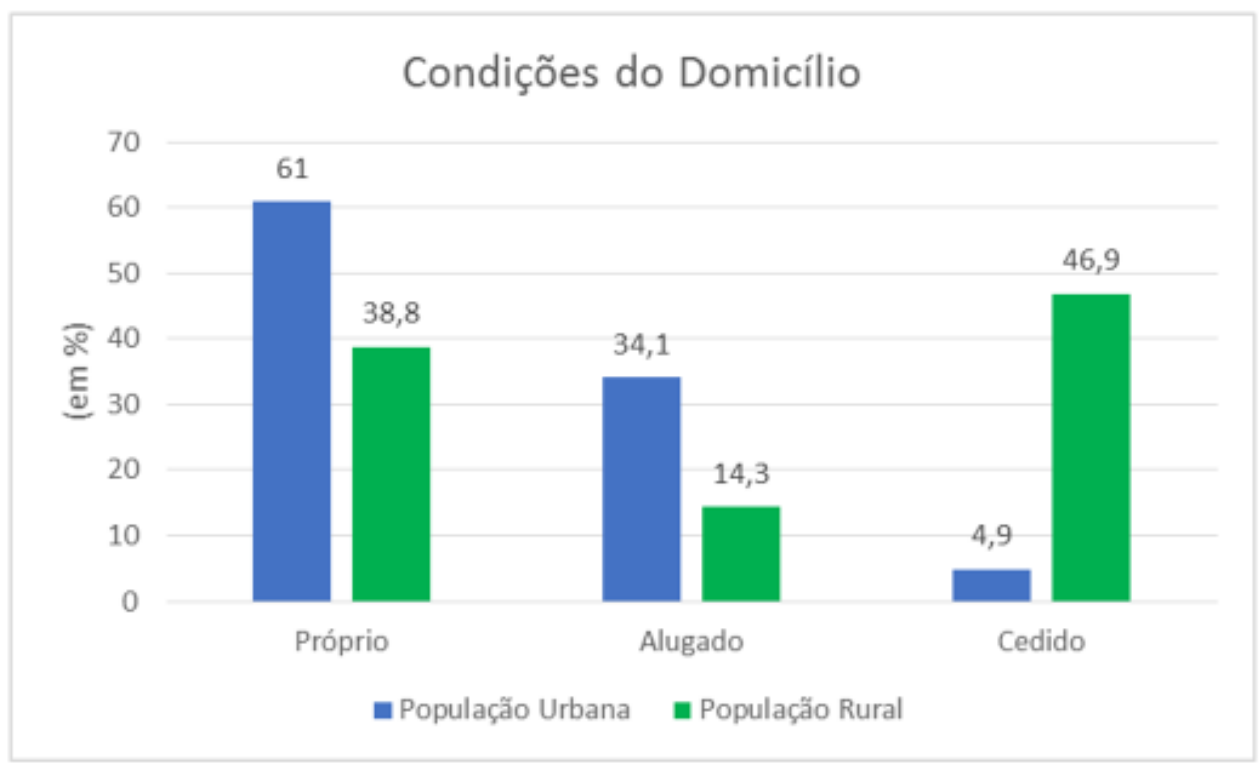

Fonte: o próprio autor, 2021

Observou-se que 46,9\% dos domicílios da zona rural encontraram-se na classe de domicílios cedidos. Essa condição de domicílio é justificada pelo fato que os trabalhadores rurais recebem dos proprietários dos estabelecimentos rurais moradia para a família, como parte das condições para se trabalhar no campo. Outra observação interessante é que na zona urbana destacou-se o número de domicílios alugados $(34,1 \%)$, evidenciando o déficit habitacional para os novos moradores e a concentração de imóveis urbanos entre os proprietários locais.

A composição da renda municipal era proveniente da agropecuária $(60 \%)$, da indústria (15\%) e do comércio (25\%) (CORUMBATAí, 2018). Considerando que mais de $50 \%$ das famílias viviam do trabalho rural, a renda familiar não era elevada, ficando abaixo de 6 salários mínimos (entre 2 a 5 mil reais).

Ao se comparar o tamanho da população e da área do município de Corumbataí com a média dos municípios Paulistas e Brasileiros, observou-se que esse se encontra bem abaixo da média Paulista e Brasileira, em termos de população, e também muito abaixo da média Brasileira, em termos de área (Tabela 2).

Tabela 2. Tamanho comparativo em termos de população e área do município de Corumbataí.

\begin{tabular}{l|c|c}
\hline $\begin{array}{l}\text { Unidade Político } \\
\text { Administrativa }\end{array}$ & $\begin{array}{c}\text { População Média por } \\
\text { Município }(\mathrm{em} \mathrm{2016)}\end{array}$ & $\begin{array}{c}\text { Área Territorial Média por } \\
\text { Município }\left(\mathrm{em} \mathrm{km}^{2}\right)\end{array}$ \\
\hline $\begin{array}{l}\text { República Federativa do do } \\
\text { Brasil }\end{array}$ & 37.088 & 1.528 \\
\hline Estado de São Paulo & 69.379 & 384 \\
\hline Município de Corumbataí & 4.045 & 278 \\
\hline \multicolumn{2}{c}{ Fonte: IBGE (2016). }
\end{tabular}

A relação entre a área e a população no município de Corumbataí gerou uma densidade demográfica considerada baixa, ao se comparar com os municípios vizinhos, e estava também muito abaixo da densidade demográfica do Estado de São Paulo (Tabela 3). 
Tabela 3. Densidade demográfica de Corumbataí e municípios vizinhos.

\begin{tabular}{|c|c|c|c|}
\hline Município & $\begin{array}{c}\text { População } \\
\text { (em hab., 2016) }\end{array}$ & $\begin{array}{c}\text { Área } \\
\left.(\mathrm{em} \mathrm{km})^{2}\right)^{*}\end{array}$ & 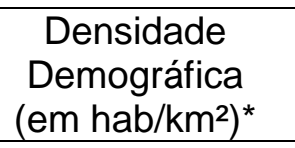 \\
\hline Rio Claro & 201.473 & 498 & 405 \\
\hline Leme & 100.296 & 403 & 249 \\
\hline Itirapina & 17.377 & 565 & 31 \\
\hline Analândia & 4.789 & 326 & 15 \\
\hline $\begin{array}{lll}\text { Santa Cruz } & \text { da } \\
\text { Conceição } & & \\
\end{array}$ & 4.371 & 150 & 29 \\
\hline Corumbataí & 4.045 & 279 & 14 \\
\hline Estado de São Paulo & 44.749 .699 & 248.220 & 180 \\
\hline
\end{tabular}

Em geral, a densidade populacional não exprime as pressões da população sobre o espaço, sendo essa determinada pela acessibilidade da população à infraestrutura socioeconômica e pela aplicação de tecnologias ao sistema produtivo. Essa simbiose entre o tamanho da população e a área do território municipal proporciona um "uso sustentável do espaço", conforme aponta Martine (2007, p 183).

Oliveira (2003) constatou que as atividades econômicas efetivadas no território municipal além de levar a uma degradação ambiental não são "suficientes para atender às necessidades de trabalho da população, que vê nas cidades vizinhas, alternativa de fixar emprego e moradia". A autora, ao fazer uma breve análise do comportamento da população local em relação às transformações do espaço geográfico, observou que:

"A população local apresentava restrições à mudança na estrutura atual da organização do espaço uma vez que outras atividades econômicas se relacionavam com mudanças de costumes e hábitos locais, que poderiam desconfigurar a situação de comodidade vivida hoje" (OLIVEIRA, 2003, p 136).

Mesmo diante destes reajustes nas atividades econômicas, a população local desfrutava de um confortável padrão de vida, tornando-a resistente à mudança. Isto se percebe ao se analisar o PIB per capita em relação aos municípios vizinhos. De acordo com o IBGE (2016), o município de Corumbataí ocupava, em 2013, a segunda colocação entre os municípios limítrofes em relação ao PIB (Produto Interno Bruto) com a média anual por pessoa de $\mathrm{R} \$ 35.717,00$. Em relação ao IDHM (Índice de Desenvolvimento Humano Municipal), em 2010, o município apresentava o índice de 0,754 (Tabela 4).

Tabela 4. PIB per capita e IDHM de Corumbataí e municípios vizinhos.

\begin{tabular}{l|c|c}
\hline MUNICÍPIO & $\begin{array}{c}\text { PIB PER CAPITA } \\
\text { (em R } \$ 1,00, \text { em 2013) }\end{array}$ & $\begin{array}{c}\text { IDHM } \\
\text { (em 2010) }\end{array}$ \\
\hline Rio Claro & $38.944,00$ & 0,803 \\
\hline Corumbataí & $35.715,00$ & 0,754 \\
\hline Santa Cruz da Conceição & $29.231,00$ & 0,790 \\
\hline
\end{tabular}




\begin{tabular}{l|c|c}
\hline Analândia & $28.953,00$ & 0,754 \\
\hline Leme & $23.670,00$ & 0,744 \\
\hline Itirapina & $18.852,00$ & 0,724 \\
\hline \multicolumn{2}{|c}{ Fonte: IBGE (2016). }
\end{tabular}

O aumento da renda regional tem levado para uma diversificação das atividades econômicas locais. Uma dessas atividades, abraçadas pela iniciativa local, começou a sinalizar para a expansão do turismo, na primeira década do século XXI.

O turismo no município de Corumbataí se realiza especialmente no meio rural, destacando o tipo Ecológico (meio ambiente natural), Rural (fazendas históricas) e de Aventura (recreação e esportes radicais), mas há também sua expressão no meio urbano, destacando o tipo Cultural (festas e patrimônio histórico) e de Eventos. A arquitetura, que compõem o espaço construído do município de Corumbataí, representada pelos patrimônios históricos, é destacada por Oliveira (2003, p 135) como uma possível inserção em um "plano de desenvolvimento turístico" (OLIVEIRA, 2003, p 135).

O potencial turístico do município é formado por sua configuração geomorfológica (serras, "cuestas", cachoeiras, grutas), pela beleza cênica (paisagens naturais, áreas para lazer), pelas propriedades rurais (fazendas históricas, artesanato rural, agronegócio), pelo patrimônio histórico e arquitetônico (olaria, cadeia pública, escola municipal, igreja, casarios antigos) e pelas áreas de lazer e banho proporcionadas pelo rio Corumbataí (MELLO, 2014, p 18; ZAMPIN, 2013).

O município de Corumbataí passou a ser representado, através da iniciativa pública e privada, no Conselho Regional de Turismo da Região Turística Serra de Itaqueri. Recentemente, Corumbataí passou também a integrar o circuito turístico "Caminho da Paz" inserido na Região Turística Histórias e Vales (CORUMBATAÍ, 2017).

O governo municipal vem reivindicando junto à Secretaria Estadual de Turismo do Estado de São Paulo a elevação do município à categoria de Município Turístico, sendo que para isso ainda deverão ser atendidos alguns critérios como a instalação de serviço médico emergencial, de infraestrutura básica e a elaboração do Plano Diretor de Turismo, conforme recomendação da Secretaria Estadual de Turismo (SÃO PAULO, 2018).

Observou-se que, durante o processo de formação econômica, ocorreu no município de Corumbataí uma substituição das propriedades dos estabelecimentos agropecuários de capitais locais para capitais externos ao município. Isso motivou o direcionamento da economia local para os interesses capitalistas regionais e nacionais, enfraquecendo a intensidade das forças econômicas e do poder político local. As transformações do território municipal são resultantes das novas ruralidades implantadas no meio rural Brasileiro, com destaque para a expansão das habitações, dos serviços e da indústria.

\section{REDE URBANA E CONTEXTO REGIONAL}

Considerando o tamanho da população e as funções urbanas, Corumbataí é classificada como uma cidade de pequeno porte que exerce apenas funções locais, fornecedoras de bens e serviços básicos à população de uma restrita área de influência, conforme aponta Fresca (2009), ao se reportar às cidades locais.

Para a análise regional do território municipal, dividiu-se o município em regiões de acordo com a orientação geográfica, situando no centro divisório regional a sede 
municipal, conforme demonstrado na Figura 4. Assim, foram estabelecidas as regiões Norte, Sul, Leste e Oeste.

As áreas de influência das cidades são delineadas a partir da intensidade das suas ligações com as outras cidades. De acordo com o IBGE (2008), as cidades foram classificadas conforme sua hierarquia urbana em cinco grandes níveis: Metrópole; Capital Regional; Centro Sub-Regional; Centro de Zona; e Centro Local. Os Centros Locais são "cidades cuja centralidade e atuação não extrapolam os limites do seu município, servindo apenas aos seus habitantes, têm população dominantemente inferior a 10 mil habitantes" (IBGE, 2008, p 13).

O território do município de Corumbataí está sob a influência direta da sede do município, atuando como um Centro Local, e também das cidades de Rio Claro, atuando como Centro Sub-Regional, nas suas porções Sul, Leste e Oeste, e da cidade de Leme, atuando como Centro de Zona, numa pequena porção Leste do município (Figura 4).

Figura 4. Corumbataí: área de influência.

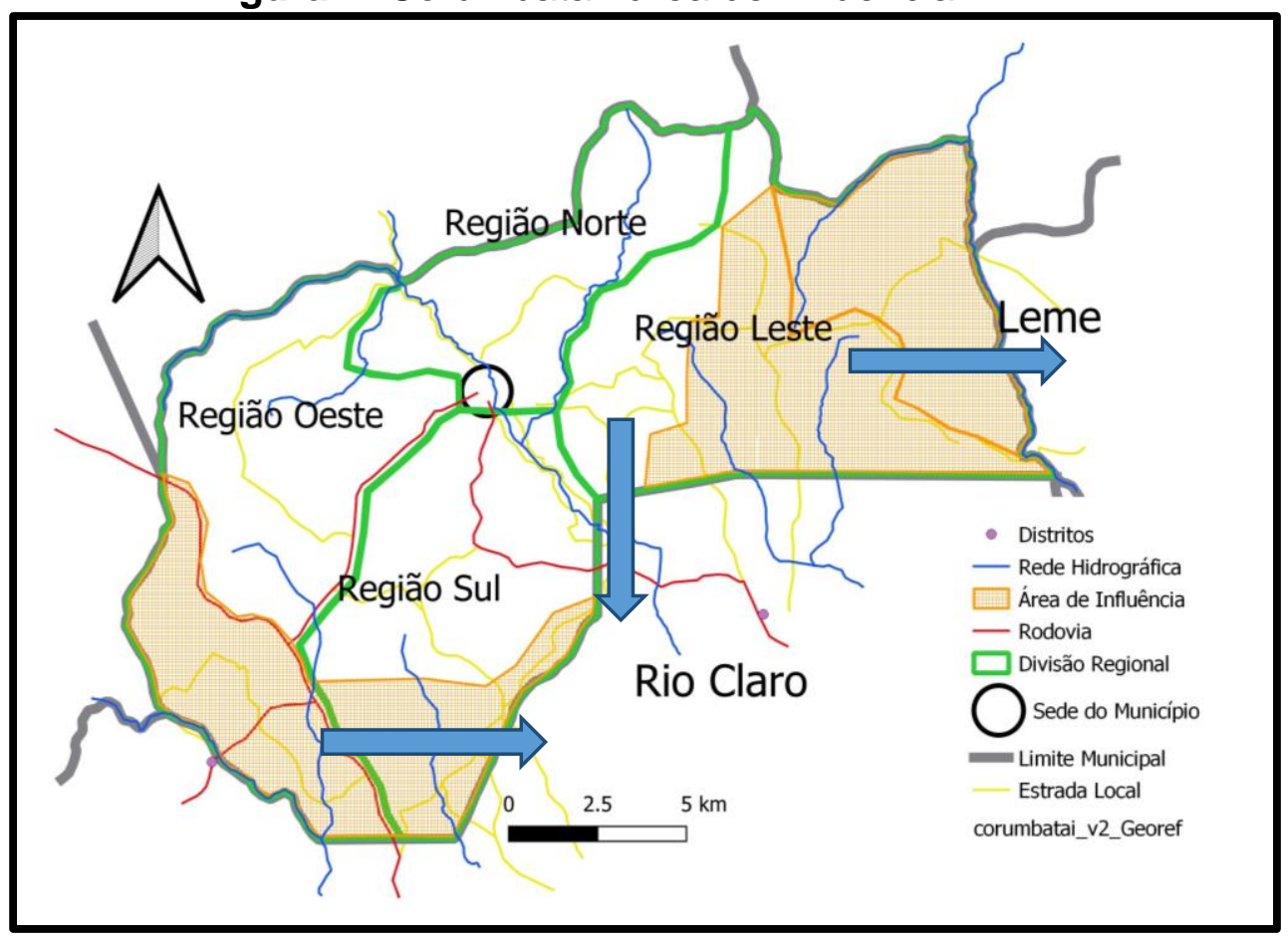

Fonte: o próprio autor, 2021

A maior influência das funções urbanas sobre o território municipal é exercida pela cidade de Rio Claro. O que se observou é que Rio Claro exerce influência direta sobre a população de Corumbataí, que habita as porções do território municipal próxima a essa cidade, ou seja, existência de fluxos diários e exclusivos, sobre as atividades de serviços e comércio, em função da distância, da facilidade de acesso e da diversidade de oferta de serviços e comércio. 
Analisando a Figura 5, nota-se que as distâncias mais curtas entre os limites municipais e os aglomerados urbanos vizinhos ocorrem em direção às cidades de Analândia e Santa Cruz da Conceição e ao distrito de Ajapi (distrito do município de Rio Claro com população de 3.059 habitantes, em 2010). Por outro lado, as distâncias mais longas entre a sede do município de Corumbataí e os pontos extremos ocorrem com as divisas dos municípios de Leme $(15,5 \mathrm{~km})$ e Rio Claro $(13,5 \mathrm{~km})$, sendo que as distâncias desses pontos extremos para a sede dos respectivos municípios vizinhos são menores: 10,8 km para Leme e 12,6 km para Rio Claro. Portanto, nesses dois extremos do município de Corumbataí há uma perda de influência direta para as cidades vizinhas, que se situam em nível hierárquico urbano mais elevado.

Figura 5. Corumbataí: distância a cidades vizinhas e pontos extremos do município.

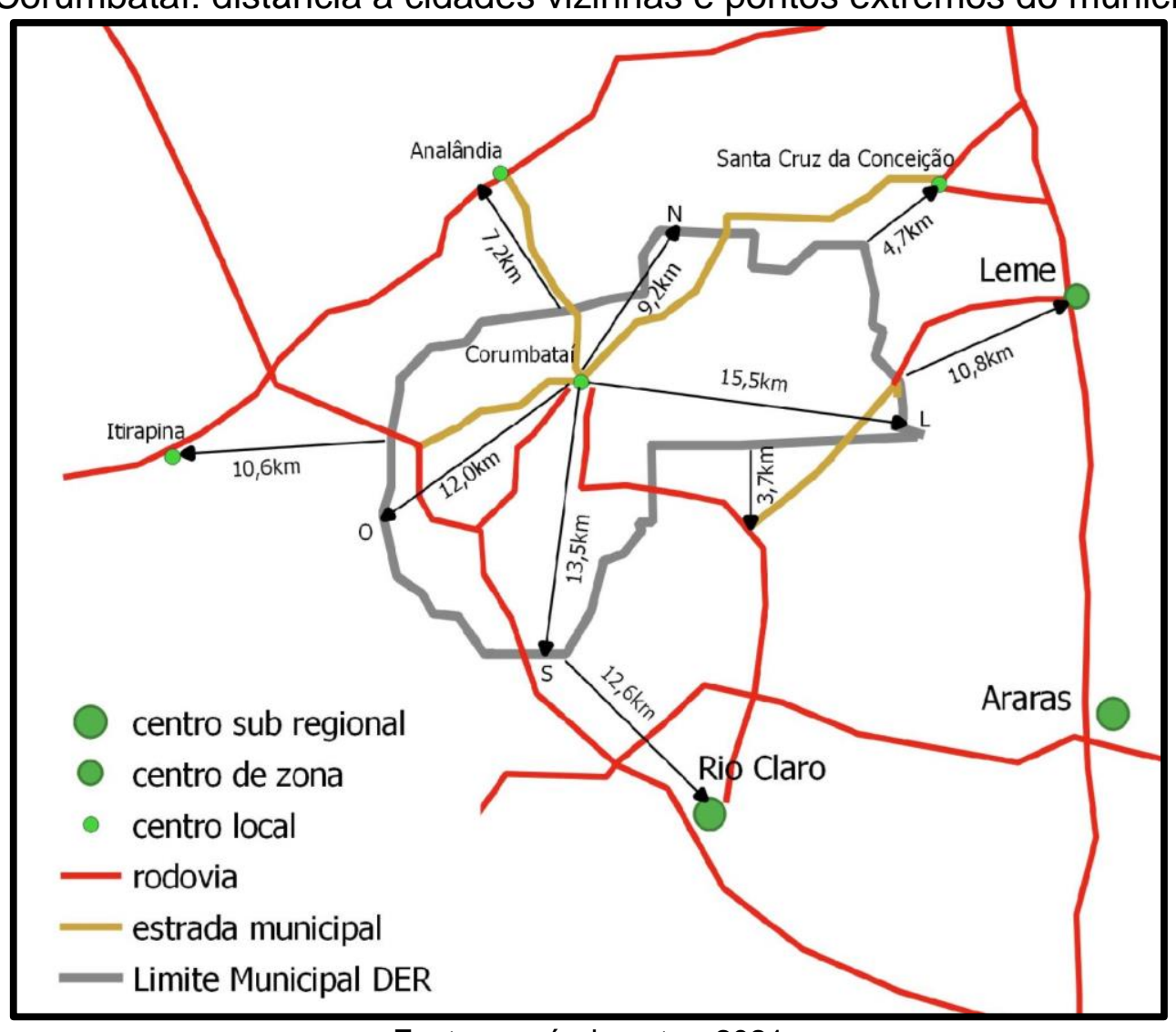

Fonte: o próprio autor, 2021 
As duas maiores cidades mais próximas de Corumbataí, que exercem a função de centros urbanos regionais, são: Rio Claro, com população estimada do município, para 2016, de 201.473 hab., distante 30 km; e São Carlos, com população estimada do município, para 2016, de 243.765 hab., distante 54 km (IBGE, 2016; DISTÂNCIA CIDADES, 2016). Considerando que a distância mais curta da cidade de Corumbataí é com a cidade de Rio Claro e que Corumbataí mantêm historicamente laços culturais e sociais e vínculos econômicos com essa cidade, Rio Claro exerce uma influência mais acentuada sobre a população de todo o município de Corumbataí.

De acordo com as Regiões de Influência das Cidades IBGE 2007 (IBGE, 2008), Corumbataí é considerada um Centro Local, sob a influência de Rio Claro (Centro Sub-Regional A), que por sua vez está relacionada com Piracicaba (Capital Regional C), vinculada à Campinas (Capital Regional A), ligadas à Grande Metrópole Nacional - São Paulo.

A Rede Urbana das cidades vizinhas à Corumbataí (IBGE, 2008) tem a seguinte formação: Itirapina (Centro Local), vinculada à São Carlos (Centro SubRegional A), vinculada à São Paulo (Grande Metrópole Nacional); Santa Cruz da Conceição (Centro Local), vinculada à Leme (Centro de Zona $B$ ), vinculada à Araras (Centro Sub-Regional B), vinculada à Campinas (Capital Regional A), vinculada à São Paulo (Grande Metrópole Nacional); Analândia (Centro Local), vinculada à Rio Claro (Centro Sub-Regional A), vinculada à Piracicaba (Capital Regional C), vinculada à Campinas (Capital Regional A), vinculada à São Paulo (Grande Metrópole Nacional).

Para Petrone (1952), a inserção regional de Corumbataí apresentava no seu período emancipatório a seguinte justificativa:

"Antes da existência da rodovia São Paulo - Rio Preto, quase toda a região do município possuía em Corumbataí o seu centro regional. Uma pequenina parte do município servia-se da estação de Itapê, na linha tronco da "C. Paulista", e outra pequenina parte da estação de Ferraz, no ramal de Analândia da mesma ferrovia" (PETRONE, 1952, p 26).

Com o início da construção da rodovia Washington Luís, no final da década de 1940, "Corumbataí viu sua influência decrescer em favor de Rio Claro" (PETRONE, 1952, p 26). A passagem da rodovia "ocasionou fortes transformações, fazendo com que algumas áreas se desenvolvessem mais, enquanto outras acelerassem 0 processo de decadência" (PETRONE, 1952, p 27).

A localização do município numa das áreas de economia mais dinâmica do estado de São Paulo, coloca o território em constante transformação e se reorganizando conforme a dinâmica se procede, principalmente conduzida pela expansão industrial com forte apelo do capital global.

Ao analisar o território municipal, a partir da Formação Socioespacial, percebese uma sintonia entre a cidade de Corumbataí e a intensidade de relação com sua rede urbana. Conforme Ferreira (2011, p 6) aponta, o conceito de "Formação Socioespacial" é útil para analisar o desenvolvimento regional e a formação da rede urbana, utilizando a periodização desse desenvolvimento e dessa formação para entender a evolução das cidades em relação recíproca com a rede urbana regional. Santos (1982) ao compreender a dimensão espacial da sociedade e da economia, reforça a inseparabilidade entre sociedade e espaço. Ao analisar o espaço geográfico de Corumbataí, com base na teoria da Formação Socioespacial, torna-se evidente 
que o território municipal é um produto da sociedade local, a qual é ao mesmo tempo seu reflexo.

A inserção do Município no contexto macrorregional, situado nos eixos de desenvolvimento do interior Paulista (SPOSITO; MATUSHIMA, 2002), torna o território municipal um importante ponto de ligação entre as diversas regiões do Estado tanto no sentido transversal (leste - oeste) quanto no sentido longitudinal (norte - sul).

No período histórico atual, a importância do contexto regional é reforçada pela decisão da Honda do Brasil de instalar uma nova unidade fabril no município de Itirapina, especificamente próxima ao entroncamento da SP $310 \mathrm{com}$ a SP 225, distante $22 \mathrm{~km}$ da cidade de Corumbataí. Este grande empreendimento da indústria automobilística Brasileira gerará empregos diretos e indiretos e impactará em toda a Microrregião Geográfica de Rio Claro (LAPOLA, 2013). A planta industrial entrou em funcionamento em 2019.

Considerando as materializações que a ação humana imprime no espaço geográfico, a formação socioespacial de Corumbataí é um produto da sociedade e também seu reflexo, sendo que sociedade e espaço se materializam na história em um processo dialético, portanto em constante transformação.

\section{PLANEJAMENTO MUNICIPAL}

O processo de ocupação humana do território municipal de Corumbataí está associado à expansão da lavoura de café, à expansão das ferrovias no interior Paulista e à política de imigração estrangeira iniciadas no final do século XIX. A rede viária local, que faz a articulação interna do município, foi construída como um reflexo desse processo de ocupação histórico.

Os sistemas de transporte atuam dialeticamente, numa dimensão histórica, na produção do espaço, onde o comportamento de um novo sistema é condicionado pelo anterior (SAQUET; SILVA, 2008). Desse modo, o sistema rodoviário torna um aspecto da organização espacial do processo de ocupação do território, como se presenciou essa configuração em diferentes estágios do desenvolvimento municipal. Percebeuse no município de Corumbataí que a organização espacial precedente girava em torno da ferrovia e, em um segundo momento, fundamentou-se na rodovia, porém condicionada, especialmente o traçado, ao primeiro sistema de transporte.

Desde sua fase Emancipatória de povoamento, o município de Corumbataí tem dificuldade de implantar políticas públicas voltadas ao desenvolvimento local devido à falta de verbas provenientes tanto de repasses estaduais e federais quanto de arrecadação própria. Santos (2005, p 156) apresenta uma solução para a administração municipal dos pequenos municípios "com a participação em projetos conjuntos tanto com a comunidade local quanto com as demais prefeituras da região" para superar as dificuldades financeiras.

De acordo com os índices socioeconômicos adotados para a Política Nacional de Desenvolvimento Regional (Quadro 1), o Ministério da Integração Nacional elaborou uma Tipologia dos Municípios Brasileiros. Nessa tipologia, Corumbataí e os municípios vizinhos se enquadraram na categoria de municípios com "Alta Renda" e "Médio Dinamismo" (BRASIL, 2017). Essa tipologia municipal é justificada pela inserção de Corumbataí no contexto regional, no qual as cidades polos, no caso Rio Claro, Limeira e São Carlos, conduzem o desenvolvimento regional, guiadas pela indústria de transformação e serviços diversificados. 
Quadro 1. Tipologia do município de Corumbataí e municípios vizinhos.

\begin{tabular}{|l|l|l|l|l|}
\hline Município & Microrregião & $\begin{array}{l}\text { Renda per } \\
\text { capita }\end{array}$ & $\begin{array}{l}\text { Crescimento do } \\
\text { PIB per capita (\%) }\end{array}$ & $\begin{array}{l}\text { Tipologia } \\
\text { regional }\end{array}$ \\
\hline $\begin{array}{l}\text { Santa Cruz } \\
\text { da Conceição }\end{array}$ & Limeira & 802,40 & 1,92 & $\begin{array}{l}\text { Alta Renda e Médio } \\
\text { Dinamismo }\end{array}$ \\
\hline Leme & Limeira & 802,40 & 1,92 & $\begin{array}{l}\text { Alta Renda e Médio } \\
\text { Dinamismo }\end{array}$ \\
\hline Analândia & São Carlos & 898,00 & 1,91 & $\begin{array}{l}\text { Alta Renda e Médio } \\
\text { Dinamismo }\end{array}$ \\
\hline Corumbataí & Rio Claro & 910,87 & 2,44 & $\begin{array}{l}\text { Alta Renda e Médio } \\
\text { Dinamismo }\end{array}$ \\
\hline Itirapina & Rio Claro & 910,87 & 2,44 & $\begin{array}{l}\text { Alta Renda e Médio } \\
\text { Dinamismo }\end{array}$ \\
\hline Rio Claro & Rio Claro & 910,87 & 2,44 & $\begin{array}{l}\text { Alta Renda e Médio } \\
\text { Dinamismo }\end{array}$ \\
\hline
\end{tabular}

Fonte: Brasil (2017)

O planejamento e a organização do território municipal, ajustados à dinâmica regional, vão potencializar as vocações locais agrícolas e não agrícolas e indicar alternativas para o desenvolvimento sustentável, para o uso do solo e para a apropriação dos recursos naturais. Esse equilíbrio sistêmico entre a dinâmica local e a regional deve acompanhar as orientações do Zoneamento Ecológico Econômico (ZEE) do Estado de São Paulo, que é um instrumento de planejamento previsto na legislação brasileira para ordenar o uso de cada território, procurando compatibilizar os recursos naturais locais com as atividades econômicas (ASN, 2016). Portanto, o ZEE deve se constituir no principal instrumento para o estabelecimento das diretrizes para a ocupação racional dos espaços locais, objetivando o melhor aproveitamento ou o redirecionamento de atividades antrópicas (SANTOS, 2005).

Esses fatores revelam que, embora seja clara a necessidade de novas alternativas de desenvolvimento, a possibilidade de desenvolvimento deve acompanhar-se de uma política que leve a população a uma maior conscientização sobre a necessidade e a viabilidade das mudanças (OLIVEIRA, 2003, p 135). As alternativas de desenvolvimento devem surgir de um modelo de gestão democrática e participativa, cujos resultados tragam benefícios que sejam compartilhados para a população local.

O desenvolvimento local sustentável exige uma sintonia entre os anseios da comunidade e as ações das políticas públicas municipal e externa, evitando conflitos de interesse socioambientais que possam inviabilizar o dinamismo econômico e a melhoria da qualidade de vida da população (MARUJO, 2013).

Vitte (2006, p 85) defende uma harmonia entre a população local e o meio geográfico, traduzidas em "políticas públicas e práticas de gestão", traçando novos caminhos para a política de desenvolvimento econômico local. Conforme apontado neste estudo, as estratégias de desenvolvimento, emanadas das políticas locais, impactarão no território e reestruturação a economia local.

O município de Corumbataí ainda caminha incipiente quanto ao aproveitamento do potencial turístico, porém apresenta potencial agropecuário e industrial elevados em segmentos específicos (SANTOS, 2005). O tripé turismo, agropecuária e indústria, apoiado no aproveitamento dos recursos naturais, indica uma alternativa segura de desenvolvimento que deve fazer parte do Plano Diretor Municipal. 
As possibilidades de investimento em Corumbataí, conforme o diagnóstico socioeconômico e a análise regional feitos, voltam-se para as áreas de turismo, com a integração regional dos atrativos turísticos, do agronegócio, envolvendo a agricultura familiar e as commodities já estabelecidas, e dos serviços urbanos, com a diversificação dos equipamentos urbanos de transporte, cultura e lazer, saúde e assistência social entre outros. A diversificação das atividades econômicas deve ser o foco principal da política pública local. Algumas precauções deveriam ser tomadas pela administração pública municipal em relação ao controle da erosão, à conservação dos recursos hídricos, à preservação da paisagem natural, formada pelo relevo e vegetação, e à solução dos entraves de infraestrutura de telecomunicação, de abastecimento de energia e de saneamento básico, que dificultam o aproveitamento das oportunidades de investimento, especialmente no meio rural.

Santos (2005) traçou uma breve avaliação das políticas públicas em Corumbataí para diferentes segmentos sociais e econômicos, destacando as ações mais representativas a serem tomadas: a) habitação de interesse social; b) educação ambiental; c) tratamento do esgoto e coleta seletiva do lixo; e d) turismo rural, ecoturismo, sinalização turística, turismo cultural - festa, festivais e encontros.

De acordo com Ortigoza (1992), as principais reivindicações da população junto à administração pública municipal eram em relação à construção de um hospital municipal, de um centro cultural e de uma área de lazer. Essas reivindicações foram parcialmente atendidas pelas administrações municipais subsequentes, sendo que na área de saúde o município conta com uma Unidade Básica de Saúde, na área de lazer foi revitalizada a área do Beira Rio e na área cultural foi reformado o Centro Comunitário Urbano. A partir dessas reivindicações, outras novas vão sendo formuladas pela comunidade local como aquela envolvendo a segurança pública.

No entanto, admite-se que os moldes de desenvolvimento econômico em que se insere o município podem levar a um quadro caótico no que concerne à degradação ambiental e ainda não é suficiente para atender às necessidades de trabalho da população, que vê "nas cidades vizinhas, alternativa de fixar emprego e moradia" (OLIVEIRA, 2003, p 135).

De acordo com Ortigoza (1992, p 45), os dados levantados e analisados, que retratavam a década de 1980, deixaram evidentes que, apesar do fraco desempenho agrícola do município, a população rural e urbana retratava uma notável qualidade de vida e uma forte integração do homem do campo com o citadino. A autora chamava a atenção para a integração que havia no município entre os moradores do campo e da cidade, caracterizando uma típica cidade de pequeno porte, onde o rural e o urbano se congregavam, levando a autora a concluir que: "há quem diz que Corumbataí é um típico bairro rural" (ORTIGOZA, 1992, p 45).

Corumbataí vê a possibilidade de desenvolvimento passar por notáveis transformações no espaço geográfico com o aproveitamento das potencialidades locais proporcionadas: a) pela rodovia Washington Luís, através do desenvolvimento comercial de suas margens, alimentado pelo grande fluxo de veículos diário; b) pela instalação da fábrica de automóveis da Honda, no município vizinho de Itirapina, demandando instalações industriais, comerciais e de prestação de serviço vinculadas e contratação de mão-de-obra; c) pelo turismo regional, com integração ao turismo de Analândia, formando uma região turística; d) pela expansão urbana e econômica de Rio Claro, cidade polo regional, provocando a diversificação das atividades econômicas; e) pelos recursos minerais, principalmente a extração de areia, aumentando o emprego e a renda municipal; e f) pela abertura de novas estradas rurais e estadualização das estradas municipais que ligam Corumbataí à Analândia, 
Corumbataí à Rio Claro e Rio Claro à Leme, que cruzam o município de Corumbataí, promovendo a integração intramunicipal e intermunicipal.

A posição estratégica do município e a existência de potencialidades locais, associadas às políticas públicas criadas por uma gestão democrática e participativa, conduzirão o município no caminho do desenvolvimento sustentável. Todas as possibilidades de desenvolvimento apresentadas poderiam estar sendo inseridas no Plano Diretor Municipal e no Plano Municipal de Turismo, que estão em fase de elaboração, e que, se envolverem os diversos segmentos da sociedade, poderão colocar o município no caminho do desenvolvimento, desde que seja de forma sustentável, democrática e participativa. Estimular a organização e a participação da comunidade local tanto urbana quanto rural, aproveitando os instrumentos institucionais já constituídos, garantirá mais eficiência às políticas públicas.

\section{CONSIDERAÇÕES FINAIS}

Procurou-se com este trabalho fazer uma análise regional dentro de um território municipal, tomando como estudo de caso o município de Corumbataí, localizado no estado de São Paulo.

Conclui-se que a organização espacial está relacionada com o processo de ocupação do território, refletindo as demandas da distribuição da população e das atividades econômicas e ao mesmo tempo instigando a ocupação do solo urbano e rural. Após análise da formação territorial e dos diferentes períodos de formação socioeconômica do município, constatou-se que a fragilidade das forças econômicas locais não acompanhou o dinamismo do desenvolvimento econômico, reduzindo a influência urbana ao nível local.

Verificou-se que o meio natural teve um papel fundamental no processo de povoamento e na definição das atividades econômicas e suas localizações. Após décadas de desmatamento da mata natural, o município se insere nos programas de proteção ambiental com destaque para a preservação dos recursos hídricos, florestais e paisagísticos. Pode ser afirmado que a vegetação e a hidrografia formam os principais patrimônios naturais do município.

A partir da análise do território municipal, foram elaboradas as estratégias de desenvolvimento para o município, tomando como referência o contexto regional no qual ele está inserido.

As informações geográficas levantadas poderão subsidiar a elaboração do Plano Diretor Municipal, com indicações para a política de desenvolvimento econômico.

A situação regional estratégica do município de Corumbataí é um importante recurso que deve ser observado pelas administrações municipais para conduzir os planos de desenvolvimento econômico. As condições impostas pela expansão do capital não devem imprimir suas regras à condução do desenvolvimento local, que deve fluir de forma democrática, participativa e sustentável.

\section{REFERÊNCIAS BIBLIOGRÁFICAS}

ASN. Agência Social de Notícias. Seção Ecodesenvolvimento. São Paulo terá finalmente o seu Zoneamento Ecológico Econômico. Campinas-SP, 24 de mar. de 2016. Disponível em: <http://agenciasn.com.br/arquivos/6465>. Acesso em: 15 de fev. de 2018. 
BRASIL. Ministério da Integração Nacional. Secretaria de Desenvolvimento Regional. Nota Técnica no 52. Proposta de atualização da Tipologia Sub-regional da Política Nacional de Desenvolvimento Regional (PNDR). Brasília-DF, 30 de nov. 2017. Disponível em: <https://www.gov.br/sudene/pt-br/centrais-deconteudo/nt522017-pdf>. Acesso em: 01 de mar. de 2018.

CORUMBATAÍ. Prefeitura Municipal. Corumbataí retoma atenção ao turismo. Disponível

em: $<$ http://www.corumbatai.sp.gov.br/index.php/19destaque/169corumbatairetomaatenc aoaoturismo?tmpl=component\&print=1\&page > . Acesso em: 20 de set. de 2017.

CORUMBATAÍ. Prefeitura Municipal. Dados Geográficos. Disponível em: $<$ http://www.corumbatai.sp.gov.br/index.php/dados-geograficos>. Acesso em: 05 de fev. de 2018.

CORVALÁN, Susana Belén. Zoneamento ambiental da APA Corumbataí (SP) de acordo com critérios de vulnerabilidade ambiental. 2009. Tese. Doutorado em Geociências e Meio Ambiente. UNESP-IGCE. Rio Claro, 2009.

DISTÂNCIA CIDADES. Calculadora de distâncias entre cidades. Disponível em: <http://www.distanciaentreascidades.com.br>. Acesso em: 30 de out. 2016.

FERLINI, Vera Lúcia Amaral; FILLIPINI, Elizabeth. Os núcleos coloniais em perspectiva historiográfica. Revista Brasileira de História, São Paulo, vol. 13, oㅡ 25/26, p 121 - 132, set. 1992, ago. 1993.

FERREIRA, Sandra Cristina. A formação socioespacial como orientação teóricometodológica no estudo da rede urbana regional. Caminhos de Geografia, Uberlândia-MG, v. 12, n. 37, p. 1 - 7, 2011.

FRESCA, Tania Maria. Pequenas cidades de rede urbana norte-paranaense e especialização em produção industrial: Re-inserções complexas. EGAL ENCONTRO DE GEÓGRAFOS DA AMÉRICA LATINA. 13. Montevideo, Uruguai, 2009.

GIESBRECHT, Ralph M. Estação Corumbataí. 2014. Disponível em: $<$ http://www.estacoesferroviarias.com.br/c/corumbatai.htm>. Acesso em: 05 de set. de 2016.

IBGE. Censo Demográfico 2010. IBGE - Instituto Brasileiro de Geografia e Estatística. Rio de Janeiro, 2010.

IBGE. Diretoria de Pesquisas - DPE - Coordenação de População e Indicadores Sociais - COPIS. Estimativa de População. Rio de Janeiro-RJ, 2016. Disponível em: $<$ https://ftp.ibge.gov.br/Estimativas de Populacao/Estimativas 2016/estimativa dou 2016 20160913.pdf>. Acesso em: 18 de mar. de 2018.

IBGE. Instituto Brasileiro de Geografia e Estatística. Regiões de influência das cidades: 2007. Rio de Janeiro: IBGE, 2008. 
LAPOLA, Marcelo. Itirapina pode sediar nova fábrica da Honda. Jornal Cidade. Notícias. Rio Claro-SP, 29 de junho de 2013.

LEITE, Catarina de F. S., JOIA, Paulo R., FERREIRA, Solange T. L. Alguns aspectos do desenvolvimento de comunidades rurais: estudo de caso de Corumbataí-SP. 1983. Monografia. Graduação em Geografia. UNESP/IGCE, Rio Claro-SP, 1983.

MARTINE, George. O lugar do espaço na equação população/meio ambiente. Revista Brasileira de Estudos de População. São Paulo, v. 24, n. 2, p. 181-190, jul./dez. 2007.

MARUJO, Marcelo Pereira. Desenvolvimento local sustentável: o empreendedorismo como condição provedora de responsabilidade socioambiental na "UPP do Batan". CONVIBRA - Congresso on line de Administração. São Paulo-SP, 2013. Disponível em: $<$ https://convibra.org/congresso/res/uploads/pdf/2013 40 7026.pdf>. Acesso em: 10 de abr. de 2018.

MELLO, Bruno Falararo de. Dinâmica pluvial e turismo em Corumbataí - SP. 2014. Dissertação. Mestrado em Geografia. UNESP/IGCE, Rio Claro, 2014.

OLIVEIRA, Regina Célia de. Zoneamento ambiental como subsídio para o planejamento de uso e ocupação do solo do município de Corumbataí - SP. 2003. Tese. Doutorado em Geociências e Meio Ambienta. UNESP/IGCE, Rio ClaroSP, 2003.

ORTIGOZA. Silvia Ap. G. As transformações na organização do espaço, no município de Corumbataí - SP, e suas consequências sociais e econômicas. 1992. Monografia. Graduação em Geografia. UNESP/IGCE - Departamento de Planejamento Regional, Rio Claro-SP, 1992.

PETRONE, Pasquale. Aspectos geográficos e problemas da região de Corumbataí. Boletim Paulista de Geografia. São Paulo, no 11, p 3-32, julho, 1952.

SANTOS, Milton. Espaço e sociedade: ensaios. Petrópolis: Vozes, 1982.

SANTOS, Shirley Cristina dos. Proposta metodológica para desenvolvimento integrado e políticas públicas na bacia hidrográfica do rio Corumbataí - SP. 2005. Tese. Doutorado em Geociências e Meio Ambiente. UNESP-IGCE, Rio ClaroSP, 2005.

SÃO PAULO. Lei n. 233, de 24 de dezembro de 1948. Fixa o quadro territorial, administrativo e judiciário do Estado, a vigorar no quinquênio 1949-1953. Anexo II. Descrição dos limites dos municípios e das divisas dos distritos de paz do Estado de São Paulo. Município de Corumbataí, p 53-54. São Paulo, 1948.

SÃO PAULO. Secretaria de Turismo. DADETUR / MIT. São Paulo-SP, 02 de abr. de 2018. 
$<$ http://www.turismo.sp.gov.br/publico/noticia tour.php?cod menu=111>. Acesso em: 27 de abr. de 2018.

SAQUET, Marcos Aurélio; SILVA, Sueli Santos da. Milton Santos: concepções de geografia, espaço e território. Geo UERJ. Rio de Janeiro, ano 10, vol. 2, n 18, p 2442, 2008.

SPOSITO, Eliseu Savério; MATUSHIMA, Marcos Kazuo. A Dinâmica Econômica no Estado de São Paulo: do paradigma de área ao paradigma de eixo de desenvolvimento. In: SILVA, João Márcio P. da; SILVEIRA; Márcio Rogério (Org.). Geografia econômica: temas regionais. Presidente Prudente-SP: FCT/UNESP/PPGG, 2002, p. 187-216.

VITTE, Claudete de Castro Silva. Gestão do desenvolvimento econômico local: algumas considerações. Interações: Revista Internacional de Desenvolvimento Local. Campo Grande-MS, vol. 8, n. 13, p. 77-87, 2006.

ZAMPIN, Ivan Carlos. Na memória a histo-geografia do município de Corumbataí SP, no decorrer do século XX, contada por seus moradores e suas moradias. Revista Unar. Araras-SP, vol. $7, \quad n^{\circ} \quad 2, \quad 2013 . \quad$ Disponível em: $<$ http://revistaunar.com.br/cientifica/documentos/vol7 n2 2013/5 memoria histo ge ografia.pdf>. Acesso em: 18 de out. de 2016.

ZANARDI, Luciana Schreiner de Oliveira. As Águas e as Margens do Rio Corumbataí: uma perspectiva de antigos moradores. 2007. Dissertação. Mestrado em Educação. UNESP-IB, Rio Claro-SP, 2007. 